\section{CASE REPORT}
A.W. Lee
C.S. Chen
P. Gailloud
P. Nyquist

\title{
Wyburn-Mason Syndrome Associated with Thyroid Arteriovenous Malformation: A First Case Report
}

SUMMARY: A 31-year-old woman with a prior history of Wyburn-Mason syndrome, complicated previously by a left thalamic intracerebral hemorrhage at age 21 , complained of sudden left vision loss due to a central retinal vein occlusion. Angiography revealed a left thyroid arterio-venous malformation (AVM) in addition to ones found intracerebrally. The pathogenesis and embryogenesis of this finding including the management of AVMs in Wyburn-Mason syndrome are discussed.

$\mathbf{W}$ yburn-Mason syndrome is an uncommon condition of brain-retinofacial angiomatosis resulting in multiple arteriovenous malformations (AVMs), usually on the ipsilateral side. ${ }^{1}$ Wyburn-Mason syndrome is now classified as a craniofacial arteriovenous metameric syndrome (CAMS). ${ }^{2}$ To date, thyroid AVMs with Wyburn-Mason syndrome have not been described. We describe a case of angiographically confirmed thyroid AVM in a clinically euthyroid patient with Wyburn-Mason syndrome. The embryology and possible pathogenesis, as well as management options for WyburnMason syndrome, are discussed.

\section{Case Report}

A 31-year-old woman with Wyburn-Mason syndrome diagnosed at age 12 years with a known retinal AVM involving the left optic disc presented with sudden loss of vision in the left eye. Examination revealed a left central retinal vein occlusion with dilated tortuous retinal veins, optic disc swelling, and widespread retinal hemorrhages in all 4 quadrants. Her past history was significant for a left thalamic intracranial hemorrhage at age 21 years requiring a prolonged intensive care admission. She had no other neurologic symptoms.

Formal 4-vessel cerebral digital subtraction angiography (DSA) was performed to evaluate the extent of her vascular malformations. It revealed a $3.0 \times 2.5-\mathrm{cm} \mathrm{AVM} \mathrm{in} \mathrm{the} \mathrm{left} \mathrm{paramedian} \mathrm{location} \mathrm{along}$ the medial aspect of the left internal carotid artery and optic tract, with an abnormal vascular blush within the left orbit and retina (Fig 1). The intracerebral AVM was fed by thalamic perforator arteries from the left posterior communicating artery (Fig 2), distal branches of the left internal carotid artery, anterior cerebral artery, and a prominent anterior choroidal artery. Incidentally, angiography also showed a left AVM of the thyroid gland (Fig 3), which is confirmed on multiple views and distinct from the laryngeal or paralaryngeal vessels. Her thyroid function tests were normal, and she has remained clinically euthyroid.

Her central retinal vein occlusion was managed expectantly with regular review to monitor intraocular pressure and to observe for neovascularization. She has experienced no further hemorrhages

Received September 18, 2006; accepted after revision October 16

From the Departments of Cerebrovascular Neurology (A.W.L., P.N.) and Neuro-Ophthalmology (C.S.C.) and Division of Neuroradiology (P.G.), Department of Radiology, Johns Hopkins Medical Institutes, Baltimore, Md.

\section{A.W.L. and C.S.C. contributed equally to this work.}

Address correspondence to Andrew W. Lee, Department of Cerebrovascular Neurology, Johns Hopkins University School of Medicine, 600 N Wolfe St, Phipps 126, Baltimore, MD 21287; e-mail: alee74@jhmi.edu

DOI 10.3174/ajnr.A0512

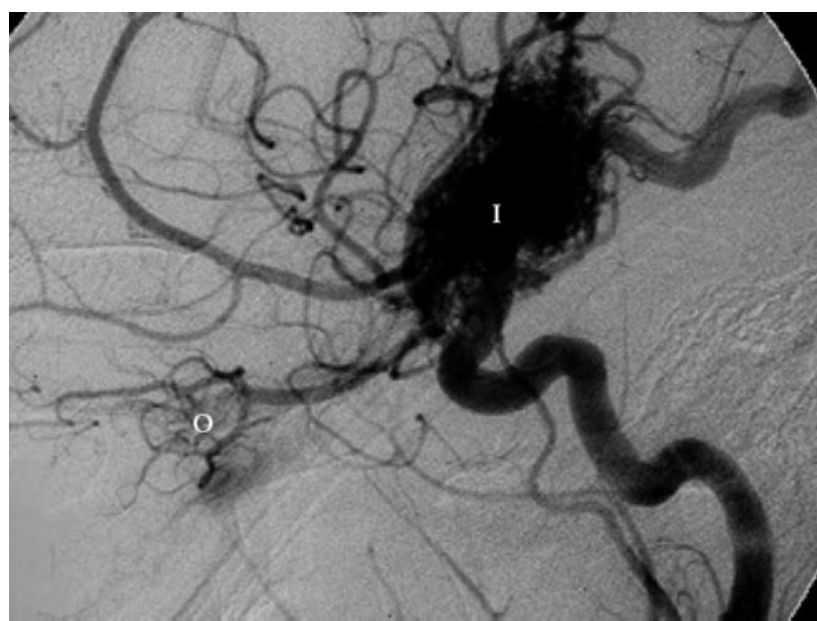

Fig 1. DSA of the left internal carotid artery, lateral view. There is an abnormal blush within the apex of the left orbit $(0)$ and a left intracerebral ( $/$ AVM extending posteriorly along the left optic nerve, tract, and radiations. This is fed by distal branches from the left internal carotid artery, as well as the anterior cerebral artery, a prominent anterior choroidal artery, and thalamic perforators from the posterior communicating artery, not demonstrated in the current view.

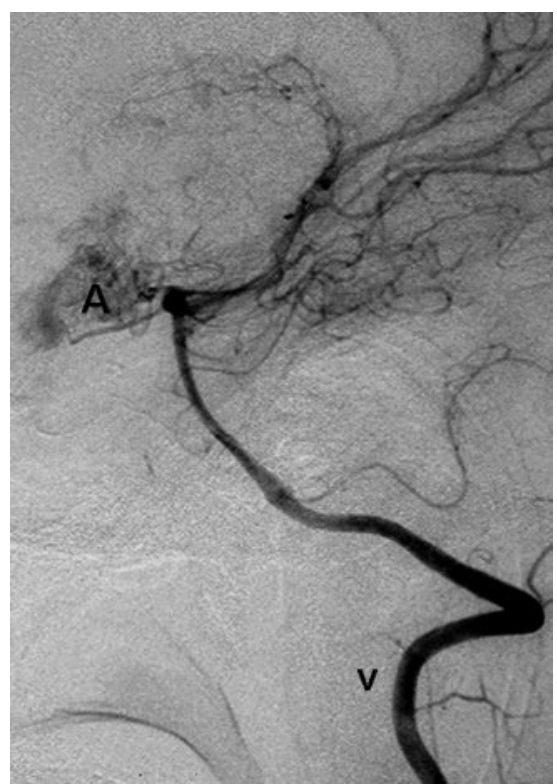

Fig 2. Lateral view of a left vertebral artery injection ( $)$ showing the same left intracerebral AVM $(A)$, as seen in Fig 1, fed by thalamic perforators arising from the left posterior communicating artery.

from the AVMs in her eye, thyroid, or brain, nor has she had evidence of optic nerve compression. 

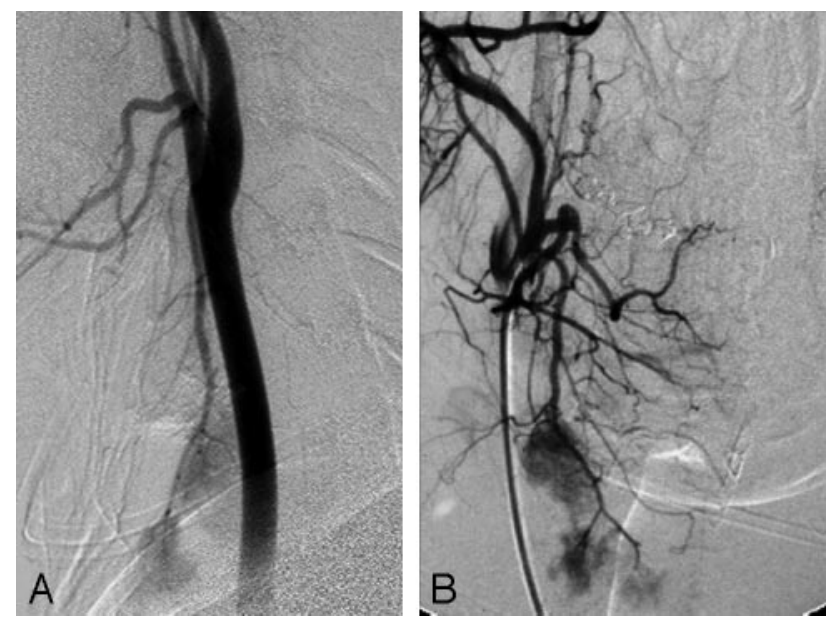

Fig 3. DSA of the right external carotid artery injection.

A, Early arterial phase, lateral view, showing 2 nodular areas of abnormal blush fed by prominent arterial branches in the thyroid gland.

$B$, Oblique view, midarterial phase, showing increase in prominence of the thyroid gland arteriovenous malformation and early draining veins (not shown here). These findings are consistent with multiple high-flow vascular malformations.

\section{Discussion}

Wyburn-Mason syndrome is a rare, nonhereditary brain-retinofacial angiomatosis. The AVMs have predilections for structures of the visual pathway, such as the retina, optic chiasm, basal ganglia, and the mesencephalon. ${ }^{3}$ Rare reports of Wyburn-Mason syndrome with AVMs involving the face, palate, pharynx, and gastrointestinal tract have also been reported. ${ }^{3}$ To our knowledge, this is the first reported case of Wyburn-Mason syndrome with thyroid gland AVMs.

Wyburn-Mason syndrome is now considered a CAMS. Bhattacharya et $\mathrm{al}^{2}$ reviewed 15 cases of Wyburn-Mason syndrome and found similarities between the distribution of the vascular lesions and the route of neural crest cell migration in avian experiments. Neural crest cells constitute the predominant connective tissue-forming mesenchyme in the facial, oral, and branchial regions of the head. They acquire a regional identity, though they are still part of the neural epithelium, and carry this with them as they move into the mandibular, hyoid, and branchial arches. ${ }^{4}$ The vascular supply of the thyroid gland derives from the third aortic arch arteries. ${ }^{5}$ Wyburn-Mason syndrome usually belongs to the CAMS-2 group originating from the lateral prosencephalon. The association of a thyroid AVM demonstrated in this patient suggests that the origin of the neural crest cells from the third branchial arch originates from the lateral prosencephalic group.

Metameric refers to a transverse level of neural crest cells. An event occurring before neural crest migration causes vascular malformations in the distribution of the corresponding metameric/transverse segment. ${ }^{6}$ The timing of the insult in this case is likely during week 7 of gestation, because the thyroid arteries arise from an invagination of the tongue endoderm in late week 4 of development and descend to their current location by week $7 .{ }^{7}$ In the eye, the optic vesicle invaginates to form the optic cups, linear grooves, and the optic fissures which have vascular mesoderm arranged in a plexus, giving rise to the retinal and hyaloid vessels. The optic cup closes at approximately 7 weeks of gestation. ${ }^{5,7}$ The nature of the insult causing this case of Wyburn-Mason syndrome with thyroid AVM is not fully known, but several genes such as BMP4 or PAX3 are important in promoting neural crest differentiation and migration in CAMS. ${ }^{8}$

The treatment of the thyroid AVM in this case of WyburnMason syndrome is expectant, because the lesion is asymptomatic. Indications for treatment of a thyroid AVM include disturbances of thyroid function or the development of a painful enlarging goiter indicating intrathyroid hemorrhage, resulting in a painful enlarging goiter. The intracranial AVMs in Wyburn-Mason tend to be more extensive and deeper than the average isolated intracranial AVM; because of the rarity of this syndrome, however, its natural history is not yet defined. ${ }^{9}$ To date, the expectant management for intracranial AVM in Wyburn-Mason or other CAMS should be approached as if it is an isolated AVM with a $2.2 \%$ per year risk of rupture in asymptomatic cases. ${ }^{10}$ Treatment modalities described include endovascular embolization, surgical extirpation, and irradiation. ${ }^{11}$

\section{References}

1. Kerrison JB. Phacomatoses. In: Miller NR, Miller NJ, Biousse V, et al eds. Walsh and Hoyt's Clinical Neuro-Ophthalmology, 6th ed. Philadelphia: Lippincott Williams \& Wilkins; 2005:1880-83

2. Bhattacharya JJ, Luo CB, Suh DC, et al. Wyburn-Mason or Bonnet-Duchaumeblanc as cerebrofacial arteriovenous metameric syndrome (CAMS) - a new concept and new classification. Intervent Neuroradiol 2001;7:5-17

3. Reck SD, Zacks DN, Eibschitz-Tsimhoni M. Retinal and intracranial arteriovenous malformations: Wyburn-Mason syndrome. J Neuroophthalmol 2005; 25:205-08

4. Noden DM. Cell movements and control of patterned tissue assembly during craniofacial development. J Craniofac Genet Dev Biol 1991;11:192-213

5. Larsen W. Human Embryology, 2nd ed. New York: Churchill-Livingston; 1997: 359,371

6. Wong IYC, Batista LL, Alvarez H, et al. Craniofacial arteriovenous metameric syndrome (CAMS) 3 - a transitional pattern between CAM 1 and 2 and spinal arteriovenous metameric syndrome. Neuroradiology 2003;45:611-15

7. O'Rahily R, Muller F. Human Embryology and Teratology. New York: Wiley-Liss Inc; 1996:149, 159, 187, 207, 329

8. Sarnat HB, Flores-Sarnat L. Embryology of the neural crest: its inductive role in the neurocutaneous syndromes. J Child Neurol 2005;20:637-43

9. Morgan MK, Johnston IH, De Silva M. Treatment of ophthalmofacial-hypothalamic arteriovenous malformation (Bonnet-Dechaume-Blanc syndrome). Case report. J Neurosurg 1985;63:794-96

10. Brown RD Jr, Wiebers DO, Forbes GS, et al. The natural history of unruptured intracranial arteriovenous malformations. J Neurosurg 1988;68:352-57

11. Riina HA, Gobin YP. Grading and surgical planning for intracranial arteriovenous malformations. Neurosurg Focus 2001;11:e3 